14-16 May, 2021

Paris, France $12^{\text {th }}$ International Conference on

Humanities, Psychology \& Social Sciences

\title{
Involuntary Neurotoxicity and Criminal Responsibility
}

\author{
Dr. Janet Brewer \\ Governors State University
}

\begin{abstract}
The intricacies of defining insanity are complicated by new insights into the inner workings of the human brain. We now know that the human brain can malfunction, even temporarily, due to conditions over which a person has no control, and this malfunction can impair a person's capacity to know what he is doing and to remember afterward what he has done. Such knowledge has spawned the defenses of diminished capacity and criminal nonresponsibility, offshoots of the insanity defense. How is responsibility to be gauged in these situations?

The first legal pronouncement of insanity in English law dates from the Wild Beast Test of 1723. Just over a century later, this defense was broadened in the case of M'Naghten, articulated by the House of Lords, which continues to shape the American Model Penal Code, a work that plays a critical part in the widespread revision and codification of the substantive criminal law of the United States. But the inherent complexities of defining insanity are compounded by new insights into the workings of the human brain. Defenses in the United States related to mental defect have morphed and changed and continued to evolve. The culpability of the criminally insane in American law during the nineteenth century was determined according to the traditional principles of English law. With little variation, defenses have held true to $M^{\prime}$ Naghten.

The unusual defense of Commonwealth v. Garabedian, the "involuntary neurotoxic damage defense," as it came to be known, was predicated on chemical poisoning of the nervous system that impeded Garabedian's capacity to control his temper. It was the first such neurological defense ever used in a criminal trial. As Garabedian formulated his unique defense based on prolonged exposure to allegedly mind-altering chemical agents, the ensuing trial called into question what role neurobiology plays in the intent to commit murder. At Garabedian's trial, the defense argued that Garabedian was under the influence of "acetylcholinesterase inhibitors," a main component of a lawn-care chemicals, and that, furthermore, involuntary exposure to the chemicals had profoundly affected Garabedian's cognitive ability. The case of Holden $v$. Elmore illustrates that the broadening neuroscientific perspective is forcing us to redefine psychology in neurophysiological terms, thus altering the traditional view of cognition and the social constructions of law that depend on it.
\end{abstract}

Keywords: insanity defense, criminal responsibility, involuntary neurotoxic damage defense, M'Naghten rule 